\title{
Infective endocarditis - can we treat it more effectively?
}

\author{
Aneta Guzek ${ }^{1}$, Wojciech Braksator ${ }^{2}$, Zbigniew Gąsior ${ }^{3}$, Mariusz Kuśmierczyk ${ }^{4}$, Jacek Różański ${ }^{4}$, \\ Zbigniew Rybicki ${ }^{5}$
}

${ }^{1}$ Department of Laboratory Diagnostics, Section of Microbiology, Military Institute of Medicine, Warsaw,

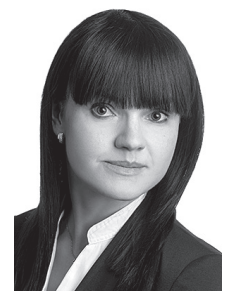
Poland

${ }^{2}$ Department of Sports Cardiology and Noninvasive Cardiac Imaging, Faculty of Medicine, Medical University of Warsaw, Warsaw, Poland

${ }^{3}$ Department of Cardiology, Medical University of Silesia, Katowice, Poland

${ }^{4}$ Department of Cardiac Surgery and Transplantology, Institute of Cardiology, Warsaw, Poland

${ }^{5}$ Department of Anesthesiology and Intensive Therapy, Military Institute of Medicine, Warsaw, Poland

Kardiochir Torakochir Pol 2020; 17 (1): 8-14

\begin{abstract}
Infective endocarditis (IE), despite the diagnostic and therapeutic advances, still remains a serious disease associated with high mortality and serious complications. The present guidelines of the European Cardiology Society of 2015 recommend administration of the antibiotics indicated in empirical therapy for multiple weeks and in targeted treatment often for $6-8$ weeks. This is associated with a risk of adverse effects of antibiotic therapy in the form of nephro- and/or hepatotoxicity and an increased risk of infections with Clostridioides difficile, while long-term hospitalisation is associated with high non-drug costs. The recommendations developed by the Austrian Society for Infectious Diseases and Tropical Medicine list dalbavancin among the new antibiotics that may find application in the treatment of IE of staphylococcal aetiology. This antibiotic is a lipoglycopeptide antibiotic alternative to vancomycin in the treatment of Staphylococcus aureus MRSA infections, especially in a situation where the minimum inhibitory concentration for vancomycin is high but below the breakpoint. Dalbavancin has very good pharmacokinetic and pharmacodynamic properties, with a long duration of action of up to 14 days after administration of a single dose $(1500 \mathrm{mg}$ in a 30-minute infusion). This antibiotic is characterised by high clinical efficacy with good treatment tolerance and safety profile, without causing toxic effects in internal organs in comparison with vancomycin. In view of its safety, clinical efficacy and convenient dosing, dalbavancin may prove a useful therapeutic option in the treatment of IE.
\end{abstract}

Key words: infective endocarditis, dalbavancin, echocardiography, Endocarditis Team.

\section{Streszczenie}

Mimo postępu diagnostyki i terapii infekcyjne zapalenie wsierdzia (IZW) jest nadal poważną chorobą, która charakteryzuje się wysoką śmiertelnością oraz występowaniem ciężkich powikłań. Aktualne rekomendacje European Cardiology Society 2015 zalecają wielotygodniowe stosowanie określonych antybiotyków w terapii empirycznej oraz w leczeniu celowanym, często przez 6-8 tygodni. Wiąże się to z ryzykiem wystąpienia objawów niepożądanych antybiotykoterapii, takich jak działanie nerko- i/lub hepatotoksyczne czy infekcja Clostridioides difficile, a długotrwała hospitalizacja łączy się z dużymi kosztami pozalekowymi. W rekomendacjach Austriackiego Towarzystwa Chorób Infekcyjnych spośród nowych antybiotyków, które mogą mieć zastosowanie w leczeniu IZW o etiologii gronkowcowej, wymienia się między innymi dalbawancynę. Lek ten jest alternatywnym do wankomycyny, lipoglikopeptydowym antybiotykiem stosowanym w leczeniu zakażeń Staphylococcus aureus MRSA, zwłaszcza gdy minimalne stężenie hamujące dla wankomycyny jest wysokie, ale poniżej punktu odcięcia, tzw. breakpointu. Ma bardzo dobre właściwości farmakokinetyczne i farmakodynamiczne, charakteryzuje się długim okresem działania - do 14 dni po podaniu jednorazowej dawki (1500 mg we wlewie 30-minutowym). Dalbawancyna cechuje się dużą skutecznością kliniczną, dobrą tolerancją i profilem bezpieczeństwa, nie wywiera toksycznego wpływu na narządy w porównaniu z wankomycyną. Ze względu na bezpieczeństwo, skuteczność kliniczną i wygodne dawkowanie może być dobrą opcją terapeutyczną w leczeniu IZW.

Słowa kluczowe: infekcyjne zapalenie wsierdzia, dalbawancyna, echokardiografia, „Grupa IZW”. 
Infective endocarditis (IE) is a disease caused by an infection of the endocardium - most commonly of the heart valves but also ventricles, atria, and large blood vessels of the chest. IE develops also subsequently to microbial colonisation of foreign bodies in cardiac chambers such as a pacemaker electrode, implanted cardioverter-defibrillator, prosthetic valves or intravascular catheters, whose presence results from past medical procedures.

Despite the diagnostic and therapeutic advances, endocarditis still remains a serious disease associated with high mortality and serious complications.

IE diagnosis in everyday clinical practice is still challenging because of its unspecific and variable clinical presentation, often at the intersection of infectious, autoimmune, rheumatic and oncological diseases.

In line with the currently valid recommendations of the European Society of Cardiology (ESC) of 2015, the following diagnostic features of IE must be considered:

1) location and presence of a prosthetic material (prosthetic valve) or implantation of a pacemaker or cardioverterdefibrillator,

2) source of infection - infection not associated with healthcare contact, nosocomial or non-nosocomial healthcareassociated infection, community-acquired infection due to injection drug use),

3) process activity - active, cured (past),

4) infection relapses: relapse $<6$ months after the first infection or reinfection within $>6$ months.

Most commonly, IE affects the aortic and mitral valves, less commonly the tricuspid vale, and in approximately $10 \%$ of cases affects more than one valve.

The incidence of IE is 3-10 cases yearly per 100,000 population [1-3]. The highest incidence is observed among persons aged 70-90 years, with a 2- to 3-fold predominance of men; it should be noted that almost a half of IE cases occur in persons without a diagnosed structural disease of the heart [4]. Approximately 3,000 new cases occur each year in Poland [5].

A particular group are intravenous users of heroin, cocaine or amphetamine. They are mostly young people, which constitutes an additional negative epidemiological factor [6]. For this reason, the incidence of IE has been increasing, and mortality ranges from $5 \%$ to $10 \%$ [7]. One large single-centre study demonstrated an increased incidence of IE caused by intravenous drug use from $14.8 \%$ in 2004 to $26.1 \%$ in $2012-2014$ [8].

The factors predisposing to IE are an elderly age of $>65$ years, male gender, history of a rheumatic disease, presence of a prosthetic heart valve, diabetes mellitus, HIV infection, long-term presence of catheters in central veins, dialysis treatment, immunosuppression, and intravenous drug use by addicts. The most common complications of IE include heart failure, renal failure, ischaemic stroke, interstitial bleeding, and septic shock.

The main causative agents of IE in adults are Gram-positive bacteria, responsible for the disease in approximately $80 \%$ to $90 \%$ of cases. In recent years, a shift in the micro- biological profile of the disease has been observed, from a streptococcal to staphylococcal causative agent. In view of their ability to colonise implanted prosthetic materials, enterococci, $>50 \%$ of which display high-level aminoglycoside resistance (HLAR), are responsible for $10-15 \%$ of infections, with 20-40\% mortality [9]. Gram-negative bacteria are a minority. They may be typical hospital bacteria with a high level of antibiotic resistance, which caused a blood infection in hospitalised patients, such as Enterobacterales spp. ESBL (+), Acinetobacter baumannii complex, Pseudomonas spp., or bacteria belonging to the HACEK group (Haemophilus spp., Aggregatibacter spp., Cardiobacterium hominis, Eikenella corrodens, Kingella spp.) as well as Coxiella burnetii, Bartonella spp., Mycoplasma pneumoniae, Brucella spp., and Legionella pneumophila. Approximately $1 \%$ are infections of fungal aetiology, mainly caused by Candida spp. [10].

The clinical presentation depends on whether the infectious process involves the left half of the heart (peripheral vascular emboli, heart failure of variable severity), or right half of the heart (pneumonia, pulmonary embolism symptoms, less commonly right ventricular failure).

The active form is diagnosed on the basis of positive blood cultures or confirmed endocarditis signs and when antibiotic treatment initiated for IE is still ongoing. Moreover, 2 main types of recurrence are distinguishable: relapse and reinfection. Relapsed IE is diagnosed when $>6$ months have passed since the original episode or when the cause of infection is a different microorganism than originally [11]. In other cases, a chronic form is recognised.

Factors associated with an increased risk of relapse include, for example, inadequate antibiotic treatment with regard to drug selection, the dose and the duration of treatment; resistance to typical antibiotic regimens; infection with resistant pathogens, e.g. atypical bacteria, Brucella spp., Coxiella burnetii, Bartonella spp., Mycobacterium spp., polymicrobial infection in intravenous drug addicts; persistent metastatic infectious foci (abscesses); positive valve cultures; chronic dialysis.

Subjective symptoms include high fever with chills or prolonged subfebrile state with associated excessive sweating, malaise, asthenia, arthralgia and myalgia, lack of appetite and weight loss, headache, nausea, dyspnoea and cough. Physical signs are heart murmurs (80\%) suggesting mitral or aortic insufficiency as a manifestation of valvular injury by the inflammatory process, emboli in vessels of different organs, neurological disorders caused by a stroke, peripheral vascular symptoms such as petechiae on the skin or under the nail plate, painful, red, raised lesions on fingers and toes (Osler's nodes), retinal haemorrhages (Roth spots) and non-painful haemorrhagic lesions on the hands and foot soles (Janeway lesions).

Noticeable findings in laboratory tests are also high levels of inflammatory markers - C-reactive protein ratio (CRP), procalcitonin, erythrocyte sedimentation rate (ESR), leucocytosis, high fibrinogen level, anaemia, microhaematuria and mild proteinuria (in $>50 \%$ of patients). High lev- 
els of inflammatory and immune markers may increase the probability but do not confirm the diagnosis of IE, as such signs lack specificity and are not included in the current diagnostic criteria.

Electrocardiographic examination also lacks specificity for the correct diagnosis of IE, because of the unspecific image of electrocardiographic changes; the abnormalities found are usually rather uncharacteristic and often overlap with a pre-existing heart defect. It may also prove useful for ruling out an acute coronary event.

IE diagnosis requires a combination of data from the clinical presentation, microbiological tests and imaging examinations, mainly transthoracic echocardiography (TTE) and transoesophageal echocardiography (TEE) [10]. In view of the above, a new algorithm for the diagnostic work-up of IE has been created, contained in the 2015 ESC guidelines. The diagnosis of IE is still based on the Duke criteria, with a particular role of echocardiography and microbiological diagnostics [11].

TTE and TEE are methods of choice for the diagnosis of $\mathrm{IE}$ and play a key role in further management and followup of patients. Three echocardiographic images constitute major diagnostic criteria of IE: vegetations (mobile or immobile structures attached to valves or other structures of the endocardium or to a prosthetic material implanted in the heart), abscess or pseudoaneurysm, and new paravalvular leak [11]. The TTE examination should be performed first in each patient when IE is suspected, while TEE is recommended for patients with a high clinical probability of infective endocarditis and normal trans-thoracic echocardiographic findings.

Echocardiography is not only limited to early diagnosis of the disease but also plays an important role in treatment monitoring, early detection of complications, surgical treatment decision making (e.g. determination of the embolic risk) and long-term follow-up.

The 2015 ESC Guidelines for the management of IE also concern the role of new imaging techniques whose use in diagnostically challenging cases makes it possible to establish the final diagnosis in most patients, such as magnetic resonance imaging (MRI) that increases the probability of detecting cerebral complications of IE; computed tomography $(\mathrm{CT})$ recommended for the assessment of coronary arteries with an associated risk of embolisation with vegetation fragments in the course of angiography, multi-slice computed tomography (MSCT), and positron emission tomography-computed tomography (PET-CT), playing an important role in the diagnosis of embolic complications and metastatic lesions, or single photon emission computed tomography (SPECT)/CT) with labelled leucocytes that enable more specific detection of IEs and inflammatory lesions different than those revealed by PET/CT [11].

Microbiological tests that include blood cultures and, in the case of IE patients undergoing a cardiac surgical procedure, intraoperative material (native or prosthetic valves, vascular prostheses, electrodes) are also important in the diagnostic work-up of IE.
The key issue for obtaining positive blood cultures is taking samples before the initiation of antibiotic treatment. A blood volume of $10 \mathrm{ml}$ (better results are obtained when the volume is increased to $20-30 \mathrm{ml}$ ) is collected into a set of two bottles with transport and culture media (1 bottle is intended for the detection of aerobic bacteria, and the second one for the detection of anaerobic bacteria). At least 3 sets of 2 bottles each should be collected at 1-hour intervals from peripheral access points (from the so-called "fresh" puncture site) [11]. In a patient with suspected catheter-induced infection, it is recommended to draw blood concomitantly from the peripheral access point and from the central vascular lines, and to collect the catheter tip.

If IE is suspected in a patient undergoing antibiotic therapy and blood cultures are negative, discontinuation of antibiotic treatment should be considered (even for 710 days), and then 3 blood sets should be collected for microbial culture.

The evidence of IE (major criterion) according to the 2015 ESC guideline are at least two positive cultures of blood samples collected 12 hours apart or of all of 3 or a majority of at least 4 samples collected at least 1 hour apart.

Endocarditis with negative blood cultures represents up to $31 \%$ of all IE cases, representing a serious diagnostic and therapeutic challenge. Negative cultures may be a consequence of prior antibiotic therapy, fungal infection or infection with atypical bacteria, especially those with obligatory intracellular growth. In such a case, it is indicated to perform serological tests for Coxiella burnetii (diagnostic titre of phase I IgG > 1 : 800) and Bartonella spp., Aspergillus spp., Mycoplasma pneumoniae, Brucella spp. and Legionella pneumophila, followed by polymerase chain reaction (PCR) assays for the presence of Tropheryma whipplei, Bartonella spp. and fungi (Candida spp., Aspergillus spp.).

Identification of the IE-causative microorganism is important for the appropriate selection of adequate antimicrobial treatment. The objective of the therapy is pathogen eradication. Treatment is difficult because of the presence of focal lesions in the vegetations with a high density of bacteria, and biofilm formation, which interferes with antibiotic penetration. Medicines are administered intravenously, and the duration and type of treatment depend on the type of the causative factor as well as on whether a native valve or a prosthetic valve is involved. In the case of treatment of a native valve infection in IE, its duration is 2- 6 weeks, and prosthetic valve IE should be treated for at least 6 weeks.

The most effective form of treatment is targeted therapy based on culture results with pathogen identification and drug susceptibility testing.

The antibiotic treatment is based in most cases on the 2015 guidelines of the European Cardiology Society that describe in detail the treatment regimens while taking into account the aetiology and location of the developing infection - a native valve (native valve endocarditis - NVE) or a prosthetic valve (prosthetic valve endocarditis - PVE). 
The above-mentioned guidelines take into account only published data from clinical trials and cohort studies investigating the efficacy of antibiotic treatment of patients with IE, while the guidelines of the Clinical and Laboratory Standards Institute (CLSI) were taken into consideration in the determination of a minimum inhibitory concentration (MIC) of an antibiotic, instead of the European Committee on Antimicrobial Susceptibility Testing (EUCAST), since most of the IE-related data were based on the CLSI values.

Empirical antibiotic treatment should be instituted as soon as possible after blood collection for culture. The choice of empirical treatment depends in particular on whether the patient has previously received antibiotics, whether the infection affects a native or a prosthetic valve, what the source of the infection is (IE not associated with healthcare contact, nosocomial or non-nosocomial healthcare-associated IE) and should take into account the local epidemiological situation as regards the occurrence of specific pathogens along with their resistance profiles.

The following empirical treatment regimens are recommended while waiting for the microbiological result in patients with IE confirmed on the basis of the clinical presentation and echocardiography:

- NVE not associated with healthcare contact or PVE that has developed $\geq 12$ months after surgery - ampicillin in combination with cloxacillin and gentamicin, or vancomycin in combination with gentamicin when the patient is allergic to $\beta$-lactams;

- early PVE (< 12 months after surgery) - vancomycin for 6 weeks in combination with gentamicin for 2 weeks and rifampicin [11], and late PVE (> 12 months after surgery) empirical treatment as in the case of NVE.

Having obtained the results of blood cultures, the treatment used so far should be modified on the basis of causative factor identification and antibiotic susceptibility testing.

In the case of a streptococcal infection:

- penicillin $G$ or amoxicillin or ceftriaxone for 4 weeks (standard treatment, 4 weeks) or penicillin G or amoxicillin or ceftriaxone in combination with gentamicin or netilmicin (shorter treatment, 2 weeks) or, in patients allergic to $\beta$-lactam antibiotics, vancomycin for 4 weeks; MIC condition for penicillin $\leq 0.125 \mathrm{mg} / \mathrm{l}$;

- penicillin $\mathrm{G}$ or amoxicillin or ceftriaxone for 4 weeks in combination with gentamicin for 2 weeks or, in patients allergic to $\beta$-lactam antibiotics, vancomycin for 4 weeks in combination with gentamicin for 2 weeks; MIC condition for penicillin 0.125-2 $\mathrm{mg} / \mathrm{l}$.

Dosage of the above antibiotics:

- penicillin G 12-18 million U/day in 4-6 doses or continuous infusion for susceptible strains (MIC $\leq 0.125 \mathrm{mg} / \mathrm{l}$ ); in relative resistance (MIC $0.25-2 \mathrm{mg} / \mathrm{l}) 24$ million U/day in 4-6 divided doses or continuous infusion,

- amoxicillin 100-200 mg/kg/day in 4-6 doses,

- ceftriaxone $2 \mathrm{~g} /$ day in 1 dose,

- gentamicin $3 \mathrm{mg} / \mathrm{kg} /$ day in 1 dose,
- netilmicin 4-5 mg/kg/day in 1 dose,

- vancomycin $30 \mathrm{mg} / \mathrm{kg} /$ day in 2 doses.

In the case of a staphylococcal infection:

1) Native valve, when the causative agent is:

- methicillin-susceptible Staphylococcus aureus methicillin (MSSA) - cloxacillin or oxacillin for 4-6 weeks or combination treatment: co-trimoxazole (intravenously for 1 week or orally for 5 weeks) in combination with intravenous clindamycin for 1 week,

- methicillin-resistant Staphylococcus aureus (MRSA) vancomycin for 4-6 weeks or daptomycin (4-6 weeks) or co-trimoxazole in combination with clindamycin.

It is not recommended to routinely add gentamicin in the treatment of staphylococcal native valve IE due to the risk of nephrotoxicity of gentamicin and the lack of evidence of its clinical benefits.

2) Staphylococcal infection of a prosthetic valve:

- MSSA - cloxacillin or oxacillin for $\geq 6$ weeks in combination with rifampicin for $\geq 6$ weeks and with gentamicin for 2 weeks,

- MRSA - vancomycin for $\geq 6$ weeks in combination with rifampicin for $\geq 6$ weeks and with gentamicin for 2 weeks [10].

Dosage of the above antibiotics:

- cloxacillin 12 g/day in 4-6 doses,

- co-trimoxazole (sulfamethoxazole $4800 \mathrm{mg} /$ day and trimethoprim $960 \mathrm{mg} /$ day in 4-6 doses),

- clindamycin $1800 \mathrm{mg} / \mathrm{kg} /$ day in 3 doses,

- daptomycin $10 \mathrm{mg} / \mathrm{kg} /$ day once daily,

- gentamicin $3 \mathrm{mg} / \mathrm{kg} /$ day in 1-2 doses,

- rifampicin 900-1200 mg/day in 2-3 doses,

- vancomycin 30-60 mg in 2-3 doses.

The trough plasma concentration of vancomycin should be $\geq 20 \mathrm{mg} / \mathrm{l}$ while in the case of an MRSA infection the recommended AUC/MIC level for vancomycin is $>400$.

Treatment of enterococcal endocarditis creates two basic issues; on one hand, enterococci are characterised by high resistance to bactericidal agents, due to which their eradication requires the use of the combination treatment extended to 6 weeks, and on the other hand, those microorganisms may have a mechanism of resistance to high concentrations of aminoglycosides (HLAR). When the IE causative agent is Enterococcus faecalis susceptible to $\beta$-lactams and gentamicin, ampicillin (amoxicillin) $200 \mathrm{mg} / \mathrm{kg} / \mathrm{day}$ for 4-6 weeks in combination with gentamicin $3 \mathrm{mg} / \mathrm{kg} /$ day in 1 dose or vancomycin $30 \mathrm{mg} / \mathrm{kg} /$ day in 2 doses together with gentamicin $3 \mathrm{mg} / \mathrm{kg} /$ day in 1 dose should be instituted.

To eradicate non-HLAR E. faecalis, combination treatment with ampicillin $200 \mathrm{mg} / \mathrm{kg} /$ day in 4-6 doses and ceftriaxone $4 \mathrm{~g}$ /day in 2 doses may be used, which demonstrates similar efficacy as ampicillin administered in combination with gentamicin. Such treatment is also safer and additionally devoid of the nephrotoxicity risk. Vancomycin in combination with gentamicin may also be used, but always with monitoring of serum concentrations of both antibiotics in view of their toxicity. 
In the case of resistance to $\beta$-lactams: 1 ) if due to $\beta$-lactamase production, ampicillin should be switched to ampicillin with sulbactam or amoxicillin should be switched to amoxicillin with clavulanic acid; 2) if due to PBP5 alteration, vancomycin-based regimens should be used. When enterococci exhibit a high level of resistance to gentamicin (MIC > $500 \mathrm{mg} / \mathrm{l})$; in the case of susceptibility to streptomycin, gentamicin should be switched to streptomycin $15 \mathrm{mg} / \mathrm{kg} /$ day in 2 divided doses.

For strains with multiple resistance to aminoglycosides, $\beta$-lactams and vancomycin, an alternative treatment is a combination of daptomycin $10 \mathrm{mg} / \mathrm{kg} /$ day with ampicillin $200 \mathrm{mg} / \mathrm{kg} /$ day in 4-6 doses or linezolid $2 \times 600 \mathrm{mg}$ for $\geq 8$ weeks or quinupristin-dalfopristin $3 \times 7.5 \mathrm{mg} / \mathrm{kg} /$ day for $\geq 8$ weeks (quinupristin-dalfopristin only for E. faecium) [11].

When the causative agents of IE are fastidious microorganisms of the HACEK group that produce $\beta$-lactamases, ceftriaxone should be administered for 4 weeks for NVE or 6 weeks for PVE, and for bacteria that do not produce $\beta$-lactamases, a therapeutic option may be ampicillin in combination with gentamicin [11].

If the causative agent is non-fermenting bacilli such as Pseudomonas aeruginosa or other Gram-negative bacteria, then third- or fourth-generation cephalosporins with antiPseudomonas activity such as ceftazidime or cefepime are used in combination with an aminoglycoside. If Enterobacteriaceae spp. or Klebsiella spp. bacilli are isolated, ceftriaxone should be used in combination with amikacin unless it is an ESBL (+)-producing strain [11].

Treatment of infectious endocarditis of fungal origin (Candida spp., Aspergillus spp.) most commonly applies to patients with a valvular prosthesis or to intravenous drug addicts and immunocompromised patients. The antifungal treatment in the case of IE caused by Candida spp. includes liposomal amphotericin (3-5 mg/kg/day) or other lipid formulations in combination with flucytosine $(100 \mathrm{mg} / \mathrm{kg} /$ day divided into 4 doses) and with echinocandins (caspofungin, micafungin, anidulafungin) at high doses, while when the causative agent is Aspergillus spp., voriconazole is recommended ( $6 \mathrm{mg} / \mathrm{kg}$ every 12 hours during the first 24 hours, followed by $4 \mathrm{mg} / \mathrm{kg}$ every 12 hours) [11].

Treatment of endocarditis with a consistently negative culture, due to such pathogens as Brucella spp., Coxiella burnetii, Bartonella spp., Legionella spp., Mycoplasma spp., Tropheryma whipplei, is presented below:

- Brucella spp. - doxycycline + co-trimoxazole + rifampicin for $\geq 3-6$ months orally; in the first few weeks streptomycin may be added in 2 divided doses,

- Coxiella burnetii - doxycycline + hydroxychloroquine (option preferred to doxycycline alone) for $>18$ months,

- Bartonella spp. - doxycycline for 4 weeks + gentamicin for 2 weeks,

- Legionella spp. - levofloxacin for $\geq 6$ weeks + clarithromycin for 2 weeks, followed by oral administration for 4 weeks + rifampicin for 6 weeks,

- Mycoplasma spp. - intravenous or oral levofloxacin for $\geq 6$ months,
- Tropheryma whipplei - doxycycline + hydroxychloroquine (option preferred to doxycycline alone) for $\geq 18$ months.

Sometimes a decision must also be made to use invasive treatment of IE which most commonly involves a cardiac surgical procedure of replacement of the destroyed valve and removal of vegetations that are present on it. In line with the 2015 ESC guidelines, in some cases surgery needs to be performed on an emergency (within 24 hours) or urgent (within a few days, $<7$ days) basis, regardless of the duration of antibiotic treatment. Indications for early surgical treatment apply to three patient groups: patients with heart failure, patients with uncontrolled infection (persistent positive blood cultures despite the appropriate antibiotic treatment) and to prevent embolic events.

An important role is also played by prophylaxis, which is indicated only in high-risk patients after dental procedures such as patients with a prosthetic valve or with prosthetic material used for cardiac valve repair; patients with previous IE, patients with untreated cyanotic congenital heart disease, and patients with congenital heart diseases after palliative surgery with shunt creation or with other prosthetic material. In the prophylaxis in high-risk patients, amoxicillin or ampicillin should be used at a dose of $2 \mathrm{~g}$ orally or intravenously, and in patients allergic to $\beta$-lactams clindamycin should be used at a dose of $600 \mathrm{mg}$ orally or intravenously [10].

The present guidelines that make use of the current pharmacological armamentarium recommend administration of the antibiotics indicated in empirical therapy for multiple weeks and in targeted treatment often for 6-8 weeks [11]. This is associated with a risk of adverse effects of antibiotic therapy in the form of nephro- and/or hepatotoxicity and an increased risk of infections with Clostridioides difficile, while long-term hospitalisation is associated with high non-drug costs. Treatment of IE in patients undergoing dialyses or in the course of immunosuppressive treatment after organ transplantation is particularly difficult and prolonged, and often has a poor outcome. The development of antibiotic tolerance may result in inhibition of bacterial growth and the lack of bactericidal efficacy of the antibiotic.

The recommendations developed by the Austrian Society for Infectious Diseases and Tropical Medicine (ÖGIT) list dalbavancin among the new antibiotics that may find application in the treatment of IE of staphylococcal aetiology [12]. This antibiotic is a lipoglycopeptide antibiotic alternative to vancomycin in the treatment of MRSA infections, especially in a situation where the MIC for vancomycin is high but below the breakpoint. Dalbavancin is characterised by low MIC values [13] in comparison with vancomycin and by bactericidal activity in contrast to the bacteriostatic properties of vancomycin, in particular against Gram-positive bacteria. Dalbavancin has very good pharmacokinetic and pharmacodynamic properties, with a long duration of action of up to 14 days after administration of a single dose (1500 mg in a 30-minute infusion), which makes it possible to shorten the hospitalisation time through discharging the 
patient in the course of treatment, and thus to reduce the treatment costs.

The medicine may also be administered in a divided dose of $1000 \mathrm{mg}$ on day 1 and $500 \mathrm{mg}$ on day 8. In a phase III study, Dunne et al. demonstrated similar effects of the medicine regardless of its dosage regimen [14].

This antibiotic is characterised by high clinical efficacy with good treatment tolerance and safety profile, without causing toxic effects in internal organs in comparison with vancomycin; in particular it is devoid of the nephrotoxic and ototoxic properties characteristic for vancomycin.

Dalbavancin is approved for the treatment of acute bacterial skin and skin structure infections (ABSSSI) in adults, but this antibiotic has also proven to be effective in methicillin-resistant staphylococcal infections such as bone infections [15], sternum infections after cardiac surgical procedures [16], catheter-induced bacteraemia [17], and infective endocarditis [17].

A large study [18] within the framework of the SENTRY Antimicrobial Surveillance Program evaluated the efficacy of dalbavancin against 626 Gram-positive strains isolated from patients with confirmed infective endocarditis in 2007-2017 from medical centres in the USA $(n=222)$ and Europe $(n=404)$. Dalbavancin and daptomycin exhibited $100 \%$ activity against S. aureus, but the MIC values for dalbavancin were 4- to 8-fold lower. Vancomycin, linezolid and teicoplanin were also active against all $S$. aureus. All E. faecalis isolates were susceptible to ampicillin, daptomycin and linezolid, while $97.6 \%$ of the isolates were susceptible to dalbavancin with $\mathrm{MIC}_{90} 0.06 \mathrm{mg} / \mathrm{l}$, while $96.7 \%$ were susceptible to vancomycin with a high $\mathrm{MIC}_{90}$ of $2 \mathrm{mg} / \mathrm{l}$. For Enterococcus faecium, $65.7 \%$ of the isolates were inhibited with MIC $\leq 0.25 \mathrm{mg} / \mathrm{l}$ for dalbavancin, and $62.9 \%$ were susceptible to vancomycin with $\mathrm{MIC}_{50} / 901 />16 \mathrm{mg} / \mathrm{l}$.

In another 2-year study [19] including 27 patients with IE caused by Gram-positive strains, clinical and microbiological success was obtained in 24 (92.6\%) patients after administration of 1 dose of dalbavancin.

In view of its safety, clinical efficacy and convenient dosing, dalbavancin may prove a useful therapeutic option in the treatment of IE.

Dalbavancin is also taken into account in considerations of outpatient continuation of antibiotic treatment in view of its long half-life, although there is no such indication within the approved labelling. Beneficial effects of outpatient continuation of the treatment of different types of Gram-positive infections with dalbavancin, including the treatment of 2 persons with an electrode-induced endocardial infection, were described in a publication by authors from Baltimore [20]. A retrospective analysis of the results of treatment of IE patients with dalbavancin in primary therapy and secondary use of dalbavancin with continuation in an outpatient setting was published by physicians of the General Hospital of Vienna [19].

Despite the attained consensus with regard to most antibiotic treatment regimens, the optimal treatment method for IE, in particular when associated with an MRSA infec- tion, is still under dispute. New reports keep appearing, most commonly on experimental studies with the use of new lipoglycopeptide antibiotics, indicating their possible applications in more severe IE forms. The long half-life, which differentiates dalbavancin from other antibiotics, raises hope for the possibility of future treatment continuation in certain patients with the use of dalbavancin in an outpatient setting. Such a treatment method would contribute to shortening of the hospitalisation time, which would certainly decrease the level of exposure of the patient to nosocomial infections and reduce the treatment costs.

Treatment of an IE patient requires the teamwork of specialists in multiple areas of medicine, such as cardiologists, cardiac surgeons, microbiologists, specialists of infectious diseases, neurologists, neurosurgeons, and ischaemic disease specialists. Modelled on the "Heart Team", the "Endocarditis Team" has been created; its members are to jointly make decisions about the selection of the optimum treatment method of IE. Such a multidisciplinary approach to the patient significantly reduces the mortality of IE patients [10].

\section{Disclosure}

The authors report no conflict of interest.

\section{References}

1. Slipczuk L, Codolosa JN, Davila CD, Romero-Corral A, Yun J, Pressman GS, Figueredo VM. Infective endocarditis epidemiology over five decades: a systematic review. PLoS One 2013; 8: e82665.

2. Pant S, Patel NJ, Deshmukh A, Golwala H, Patel N, Badheka A, Hirsch GA, Mehta JL. Trends in infective endocarditis incidence, microbiology, and valve replacement in the United States from 2000 to 2011. J Am Coll Cardiol 2015; 65: 2070-2076.

3. Bustamante-Munguira J, Mestres CA, Alvarez P, Figuerola-Tejerina A, Eiros Bachiller R, Gómez-Sánchez E, Alvarez FJ, Resino S, Castrodeza J, Tamayo E. Surgery for acute infective endocarditis: epidemiological data from a Spanish nationwide hospital-based registry. Interact Cardiovasc Thorac Surg 2018; 27: 498-504.

4. Cahill TJ, Prendergast BD. Infective edndocarditis. Lancet 2016; 387: 882-893.

5. Stępińska J, Undas A. Choroby wsierdzia. In: Szczeklik A (ed.). Choroby wewnętrzne - stan wiedzy na rok 2011. Medycyna Praktyczna, Kraków 2011; 326-338

6. Yanagawa B, Bahji A, Lamba W, Tan DH, Cheema A, Syed I, Verma S. Endocarditis in the setting of IDU: multidisciplinary management. Curr Opin Cardiol 2018; 33: 140-147

7. Miró JM, del Río A, Mestres CA. Infective endocarditis and cardiac surgery in intravenous drug abusers and HIV-1 infected patients. Cardiol Clin 2003; 21: 167-184

8. Shetty N, Nagpal D, Koivu S, Mrkobrada M. Surgical and medical management of isolated tricuspid valve infective endocarditis in intravenous drug users. J Card Surg 2016; 31: 83-88.

9. Miro JM, Pericas JM, del Rio A. Enterococcus faecalis endocarditis: ampicillin plus short-course gentamicin or ampicillin plus ceftriaxone: that is the question! Circulation 2013; 127: 1763-1766

10. Rybicki Z. Antybiotykoterapia w problematyce zakażeń szpitalnych. Wyd. Medyczne Makmed, Lublin 2015.

11. Habib G, Lancellotti $P$, Antunes MJ, Bongiorni MG, Casalta JP, Del Zotti F, Dulgheru R, El Khoury G, Erba PA, lung B, Miro JM, Mulder BJ, PlonskaGosciniak E, Price S, Roos-Hesselink J, Snygg-Martin U, Thuny F, Tornos Mas P, Vilacosta I, Zamorano JL; ESC Scientific Document Group. 2015 ESC guidelines for the management of infective endocarditis: the Task Force for the Management of Infective Endocarditis of the European Society of Cardi 
ology (ESC). Endorsed by: European Association for Cardio-Thoracic Surgery (EACTS), the European Association of Nuclear Medicine (EANM). Eur Heart J 2015; 36: 3075-3128.

12. Thalhammer F, Apfalter P, Frick M, et al. Die infektiöse Endocarditis. Consensus Statement. Österreichische Ärzte Zetung 2016; August Supplement: 1-12.

13. Guzek A, Rybicki Z, Tomaszewski D. In vitro analysis of the minimal inhibitory concentration values of different generations of anti-methicillinresistant Staphylococcus aureus antibiotics. Indian J Med Microbiol 2018; 36: 119-120.

14. Dunne MW, Puttagunta S, Giordano P, Krievins D, Zelasky M, Baldassarre J. A randomized clinical trial of single-dose versus weekly dalbavancin for treatment of acute bacterial skin and skin structure infection. Clin Infect Dis 2016; 62: 545-551.

15. Dunne MW, Puttagunta S, Sprenger CR, Rubino C, Van Wart S, Baldassarre J. Extended-duration dosing and distribution of dalbavancin into bone and articular tissue. Antimicrob Agents Chemother 2015; 59: 1849-1855.
16. Guzek A, Suwalski G, Tomaszewski D, Rybicki Z. Dalbavancin treatment in a deep sternal wound MRSA infection after coronary artery bypass surgery: a case report. J Cardiothorac Surg 2018; 13: 3

17. Smith JR, Roberts KD, Rybak MJ. Dalbavancin: a novel lipoglycopeptide antibiotic with extended activity against Gram-positive infections. Infect Dis Ther 2015; 4: 245-258.

18. Sader HS, Mendes RE, Pfaller MA, Flamm RK. Antimicrobial activity of dalbavancin tested against Gram-positive organisms isolated from patients with infective endocarditis in US and European medical centres. J Antimicrob Chemother 2019; 74: 1306-1310.

19. Tobudic S, Forstner C, Burgmann H, Lagler H, Ramharter M, Steininger C, Vossen MG, Winkler S, Thalhammer F. Dalbavancin as primary and sequential treatment for Gram-positive infective endocarditis: 2-year experience at the General Hospital of Vienna. Clin Infect Dis 2018; 67: 795-798.

20. Bork JT, Heil EL, Berry S, Lopes E, Davé R, Gilliam BL, Amoroso A. Dalbavancin use in vulnerable patients receiving outpatient parenteral antibiotic therapy for invasive Gram-positive infections. Infect Dis Ther 2019; 8: 171-84. 